\title{
The intercostobrachial nerve as a sensory donor for hand reinnervation in brachial plexus reconstruction is a feasible technique and may be useful for restoring sensation
}

0 uso do nervo intercostobraquial como doador na restauração cirúrgica da sensibilidade da mão em lesões do plexo braquial é uma técnica anatomicamente viável e pode ser útil para a recuperação sensitiva Luciano Foroni', Mário Gilberto Siqueira¹, Roberto Sérgio Martins', Gabriela Pintar Oliveira²

\begin{abstract}
Objective: Few donors are available for restoration of sensibility in patients with complete brachial plexus injuries. The objective of our study was to evaluate the anatomical feasibility of using the intercostobrachial nerve (ICBN) as an axon donor to the lateral cord contribution to the median nerve (LCMN). Methods: Thirty cadavers were dissected. Data of the ICBN and the LCMN were collected, including diameters, branches and distances. Results: The diameters of the ICBN and the LCMN at their point of coaptation were $2.7 \mathrm{~mm}$ and $3.7 \mathrm{~mm}$, respectively. The ICBN originated as a single trunk in $93.3 \%$ of the specimens and bifurcated in $73.3 \%$. The distance between the ICBN origin and its point of coaptation to the LCMN was $54 \mathrm{~mm}$. All ICBNs had enough extension to reach the LCMN. Conclusion: Transfer of the ICBN to the LCMN is anatomically feasible and may be useful for restoring sensation in patients with complete brachial plexus injuries.
\end{abstract}

Keywords: brachial plexus; intercostal nerves; median nerve; nerve transfer; sensation.

\section{RESUMO}

Objetivo: Poucos doadores estão disponíveis para a restauração da sensibilidade em pacientes com lesões completas do plexo braquial (LCPB). O objetivo deste estudo foi avaliar a viabilidade anatômica do uso do nervo intercostobraquial (NICB) como doador de axônios para a contribuição do cordão lateral para o nervo mediano (CLNM). Métodos: Trinta cadáveres foram dissecados. Os dados do NICB e do CLNM foram coletados: diâmetros, ramos e distâncias. Resultados: Os diâmetros do NICB e da CLNM no ponto de coaptação foram 2,7mm e 3,7mm, respectivamente. O NICB originou-se como um único tronco em 93,3\% dos espécimes e bifurcou-se em 73,3\%. A distância entre a origem do NICB e seu ponto de coaptação com a CLNM foi de $54 \mathrm{~mm}$. Todos os NICBs tiveram extensão suficiente para alcançar a CLNM. Conclusão: A transferência do NICB para a CLNM é anatomicamente viável e pode ser útil para restaurar a sensibilidade em pacientes com LCPB.

Palavras-chave: plexo braquial; nervos intercostais; nervo mediano; transferência de nervo; sensação.

The main target of surgical reconstruction in patients with severe traumatic injury of the brachial plexus is motor recovery, with special attention to proximal muscles of the arm. A second target is sensory recovery of the hand to gain protection. Although it is not a common practice in most cases, sensory restoration of an anesthetic hand should be included in the surgical management of these patients.

Transfers of supraclavicular (SCN) and intercostal nerves (ICNs) to the lateral contribution of the median nerve (LCMN) for this purpose have been reported but the studies had a small number of patients and the results were inconsistent ${ }^{1,2,3,4,5}$.

The intercostobrachial nerve (ICBN) arises from the second intercostal nerve as its lateral cutaneous branch ${ }^{6}$, and the axilla and posteromedial aspect of the arm has been related as its cutaneous area of innervation ${ }^{7}$. This nerve has been described in anatomical and clinical studies of axillary approaches to metastatic cancer, lymph node clearance, breast cancer and plastic surgery $8,9,10,11,12,1,1,14$. The use of the

${ }^{1}$ Universidade de São Paulo, Faculdade de Medicina, Hospital das Clínicas, Divisão de Neurocirurgia, São Paulo SP, Brasil;

${ }^{2}$ Universidade de São Paulo, Faculdade de Medicina, São Paulo SP, Brasil.

Correspondence: Luciano Foroni; Instituto de Psiquiatria - Divisão de Neurocirurgia Funcional; Av. Dr. Ovídio Pires de Campos, 785 / $2^{\circ}$ andar; $01246-903$ São Paulo SP, Brasil; E-mail: lucianoforoni@yahoo.com.br

Conflict of interest: There is no conflict of interest to declare.

Received 03 February 2017; Accepted 15 February 2017. 
ICBN as a donor nerve for brachial plexus injury was once described by Hattori et al. ${ }^{15}$, but in association with ICNs and with no anatomical background study.

The purposes of this study were to determine the anatomical feasibility of using the ICBN as a sensory donor in a nerve transfer to the lateral cord contribution to the median nerve (LCMN) (Figure 1), and to compare the ICBN with the $\mathrm{SCN}$ and the lateral cutaneous branch of the third intercostal nerve $\left(3^{\text {rd }} \mathrm{ICN}\right)$ in terms of the number of fibers.

\section{METHODS}

\section{Anatomical study}

A prospective study of 30 non-fixed cadavers was performed from September 2010 to October 2011. For standardization, dissections were performed on the right side in supine position with the right arm abducted 45 degrees. The SCN, the ICBN, the $3^{\text {rd }} \mathrm{ICN}$ and the LCMN were dissected by supraclavicular, thoracic-axillary and infraclavicular approaches, respectively.

The SCN is a very superficial nerve that emerges as a single trunk from the cervical plexus (ventral rami of $\mathrm{C} 3$ and mainly C4 spinal nerves) and innervates the skin over the upper chest and shoulder. It was dissected in the supraclavicular region, in its descending route in the posterior triangle of the neck underneath the platysma muscle, separating it from the surrounding subcutaneous tissue. Then, a longitudinal incision was made along the anterior axillary line starting in the posterior part of the lateral border of the pectoralis major muscle and prolonging downward until the fourth intercostal space. The fat tissue in the axillar region was dissected and mobilized carefully. The ICBN and the $3^{\text {rd } I C N}$ were identified within this fat tissue, emerging from the second and third intercostal spaces, respectively, and dissected distally towards the lateral chest skin and axillar region. The ICBN was then reflected towards the infraclavicular space to reach the LCMN below the pectoralis major muscle. Finally, a deltopectoral incision was made, the cephalic vein was mobilized and the deltoid and the pectoralis major muscles were retracted. The pectoralis minor muscle was identified, arising from the coracoid process, and was divided to expose the infraclavicular plexus beneath the fat pad. The LCMN was isolated and divided at its origin in the lateral cord to be turned down towards the axilla for coaptation with the ICBN.

Photographs (Nikon Coolpix S630, Tokyo, Japan) were taken of important details of all dissections, some of which were selected to illustrate the study.

Data on age, sex, height and weight were obtained and the following information about the ICBN were collected: the diameter and the number of branches at its origin and at its distal part, the distance between its origin and ramifications,
A

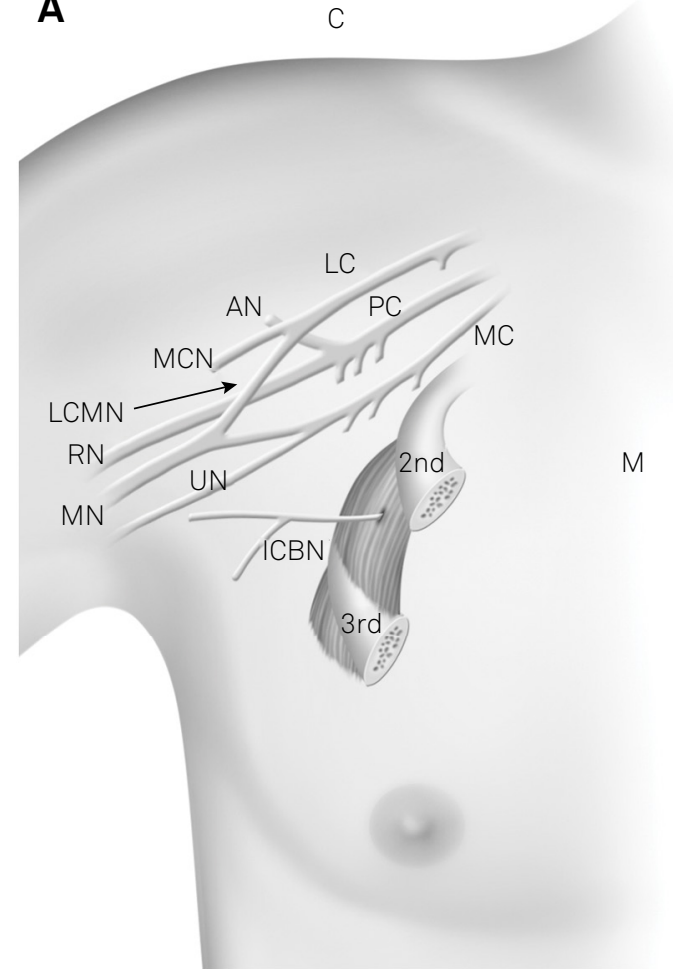

B

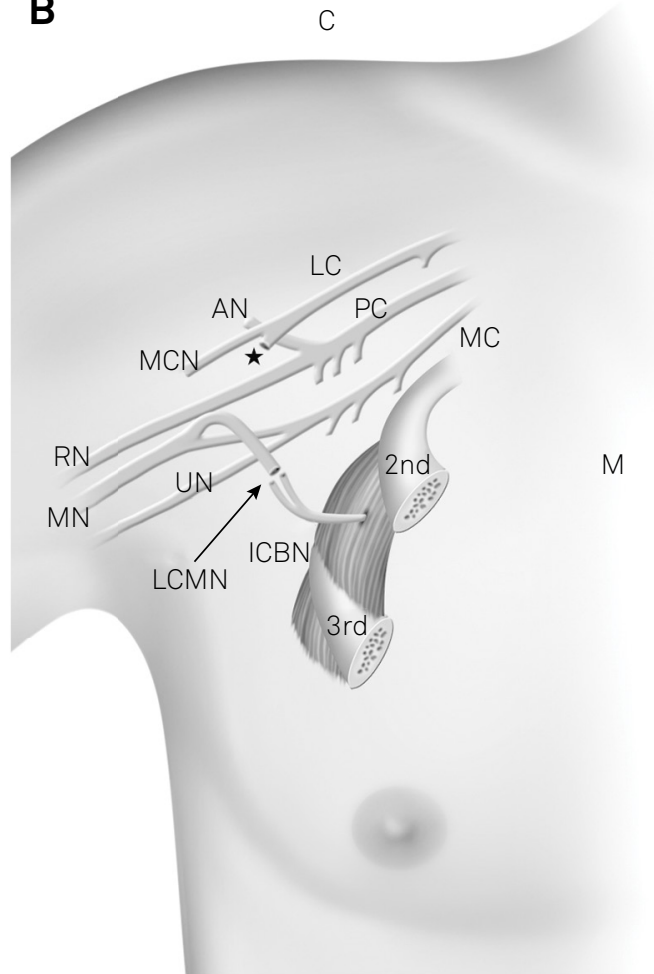

$2^{\text {nd }}$ : second rib; $3^{\text {rd }}$ : third rib; AN: axillary nerve; C: cranial; ICBN: intercostobrachial nerve; LC: lateral cord; LCMN: lateral cord contribution to the median nerve; M: medial; MC: medial cord; MCN: musculocutaneous nerve; MN: median nerve; PC: posterior cord; RN: radial nerve; UN: ulnar nerve; * point where the LCMN is sectioned from the LC to be turned inferiorly for coaptation with the ICBN

Figure 1. Schematic drawing of the nervous structures in the axilla (a) and of the proposed nerve transfer of the intercostobrachial nerve to the lateral cord contribution to the median nerve (b) (From the authors archive). 
the diameter at the point of coaptation to the LCMN in the nerve transfer proposed and the distance between its origin and the point of coaptation to the LCMN. Measurements of the LCMN diameter at the point of coaptation were also collected. The measures were made with a plastic pachymeter (Vonder, Tianjin, China).

In the last ten cadavers dissected, the nerve fragments were collected for processing and histomorphometric analysis. The three nerves (SCN, ICBN, $3^{\text {rd }} \mathrm{ICN}$ ) were sectioned as distally as possible, and the distal fragments were then obtained. The LCMN was sectioned as proximally as possible after its microsurgical separation from the lateral cord, and a fragment was obtained from this extremity. These procedures were performed to simulate the real conditions identified in the nerve transfer surgery (Figure 2).

The Ethics Committee previously approved this study.

\section{Histomorphometric analysis and fiber counting}

The fragments of the four nerves (SCN, ICBN, $3^{\text {rd } I C N}$ and LCMN) were fixed in a paraformaldehyde solution (4\% in saline solution, pH 6.9) for 24 hours and then cryopreserved in a $10 \%$ saccharose solution and frozen in isopentanol $\left(-60^{\circ} \mathrm{C}\right)$. Adjacent serial thaw-mounted $14 \mu \mathrm{m}$ sections were obtained with a cryostat from the nerve fragments. The sections were sampled systematically during sectioning. One section from each nerve fragment was obtained. Immunoreactivity for the neurofilament 200 kDa (NF-200, Sigma, St. Louis, USA) was assessed $^{16}$. For this, sections were washed for 3x10 min in PBS and incubated with $5 \%$ milk for $60 \mathrm{~min}$, followed by $0.05 \%$ hydrogen peroxide for $45 \mathrm{~min}$. The sections were washed again in PBS (3 x 10 min) and incubated with NF-200 diluted 1:2200 for $48 \mathrm{~h}$. Immunoreactivity was visualized using 3-3'-diaminobenzidine tetrahydrochloride as a chromogen.
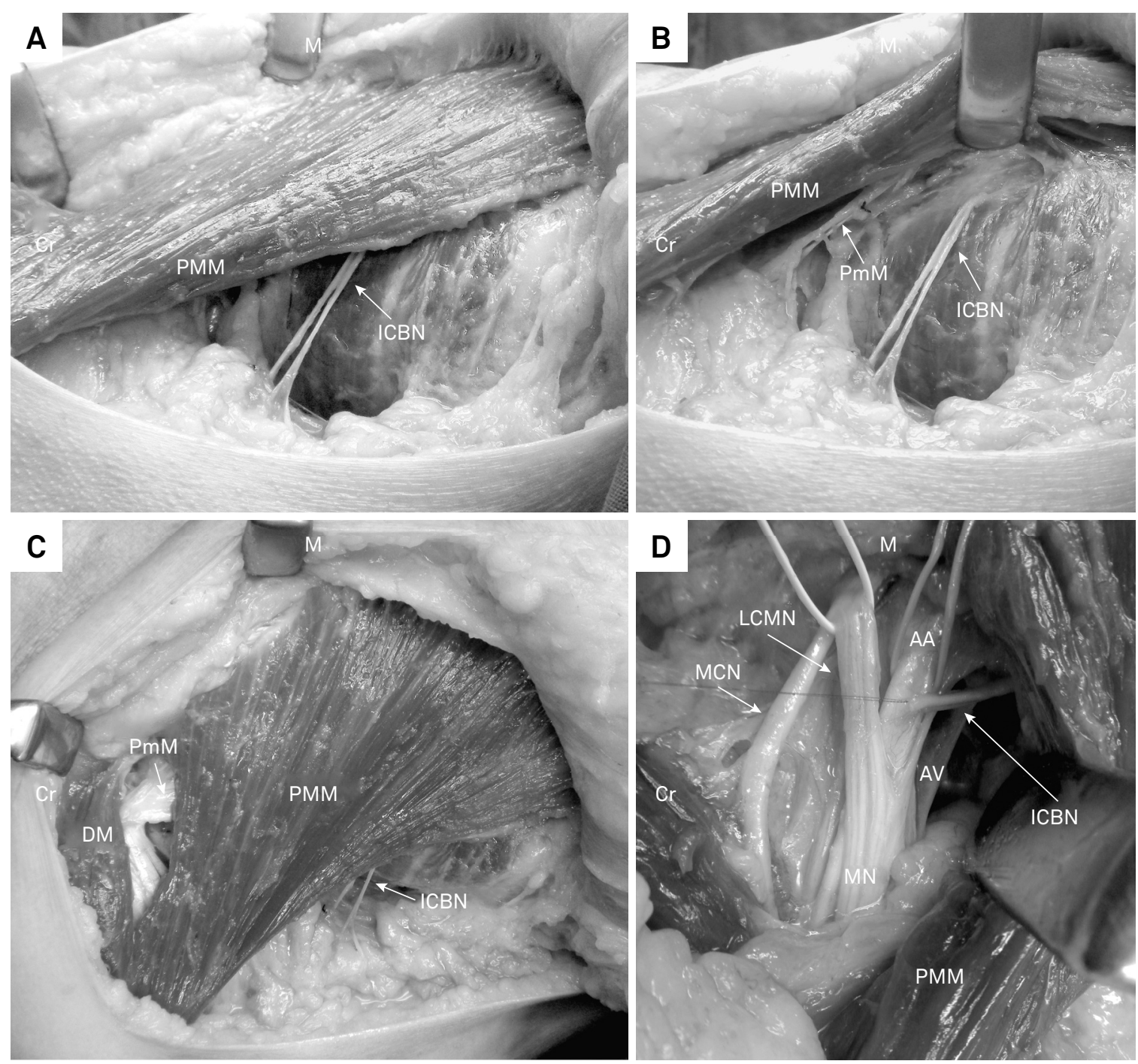

AA: axillary artery; AV: axillary vein; Cr: cranial; DM: deltoid muscle; ICBN: intercostobrachial nerve; LCMN: lateral cord contribution to the median nerve; M: medial; MCN: musculocutaneous nerve; MN: median nerve; PMM: pectoralis major muscle; PmM: pectoralis minor muscle.

Figure 2. Photos of anatomical dissections: a) lateral view of the thorax showing the intercostobrachial nerve under the pectoralis major muscle; b) intercostobrachial nerve origin in the second intercostal space; c) anterior view of the thorax showing the intercostobrachial nerve in its original position; d) after being sectioned distally and displaced in the subpectoral space, the intercostobrachial nerve reaches the elements of the brachial plexus in the deltopectoral groove (From the authors archive). 
This process resulted in fibers that were marked and able to be counted. The sections were analyzed and photographed with a photomicroscope (Olympus AX70, Tokyo, Japan). Quantification of the fibers was performed using stereology in microphotographs of each nerve using Adobe Photoshop $5 \mathrm{~S}$ software (San Jose, USA) with a magnification of 40x.

\section{Statistical analysis}

The values were expressed as the mean \pm standard deviation. Statistical analysis was performed using SPSS version 20.0.0 software (Chicago, USA). After evaluating the sample distribution with a Shapiro-Wilk test and the equality of variances using the MANOVA, the paired t-test was used to compare the number of fibers of the potential donors (SCN, ICBN and $\left.3^{\text {rd }} \mathrm{ICN}\right)$ with each other and with the recipient nerve (LCMN). A p value less than 0.05 was considered statistically significant.

\section{RESULTS}

Of all cadavers, twenty-two were male and eight were female, with a mean age, height and weight of 62 years (range $33-83$ y), $165 \pm 9 \mathrm{~cm}$ and $59.5 \pm 12.8 \mathrm{Kg}$, respectively.

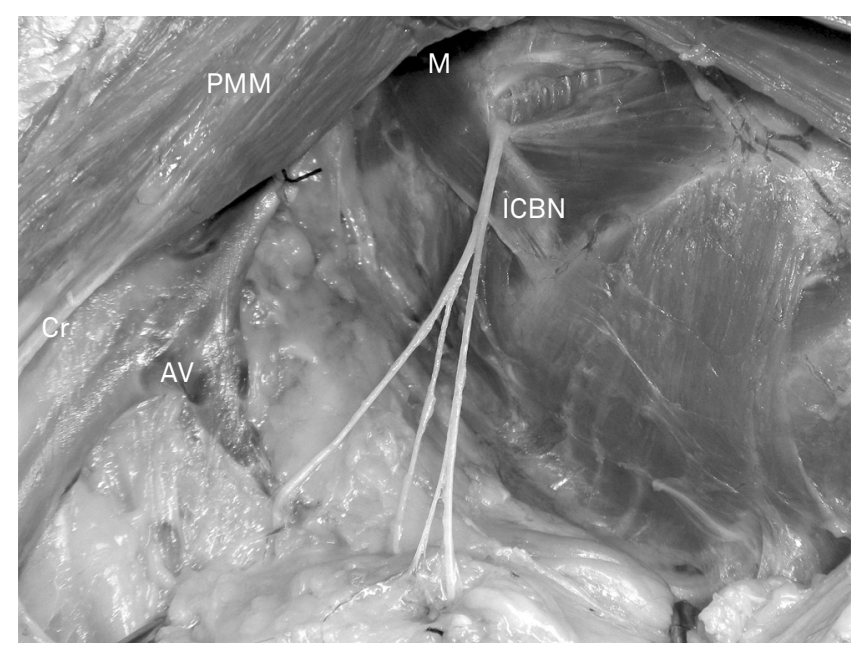

AV: axillary vein; Cr: cranial; ICBN: intercostobrachial nerve; M: medial; PMM: pectoralis major muscle

Figure 3. Photo of anatomical dissection: lateral view of the axilla showing the origin of the ICBN and its ramifications (From the authors archive).
The intercostobrachial nerve was present in all cadavers during the axillary dissections, piercing the serratus anterior muscle and emerging under the second rib. All of the ICBNs dissected had enough extension to directly reach the LCMN, with an average distance of $54 \pm 10 \mathrm{~mm}$ from their origin to the point of coaptation with the recipient nerve.

The mean diameter of ICBN at its origin and at the point of coaptation was $2.08 \pm 0.67 \mathrm{~mm}$ and $2.74 \pm 0.87 \mathrm{~mm}$, respectively. The mean diameter of the LCMN was $3.69 \pm 1.07 \mathrm{~mm}$.

Twenty-eight (93.3\%) ICBNs were single trunk at their origins, with only one already divided into two and another into three branches at their origin in the second intercostal space.

There was a variation of branching in the axillary course until it reached the arm. Seven nerves had divided into three branches distally, 22 had two branches and one reached the arm as a single trunk (Figure 3). Four of them had a communication with the brachial plexus and one was connected to the lateral cutaneous branch of the third intercostal nerve. Apparently, because of their angulation, these communications seem to be a contribution from the ICBN to the elements of the brachial plexus (medial brachial cutaneous nerve) (Figure 4). The anatomical data are summarized in Table 1.

The mean number of fibers in the ICBNs was $984 \pm 517$, $470 \pm 266$ in the ICNs, $693 \pm 511$ in the SCNs and $5273 \pm 1134$ in the LCMNs. Detailed data on the fiber counting are shown in Table 2 . The ICBN number of fibers was significantly greater than the $3^{\text {rd }} \mathrm{ICN}$ number of fibers $(\mathrm{p}=0.012)$. Although the mean values of the ICBN (984 fibers) and the SCN (693 fibers) were discrepant, the statistical analysis showed no significant difference between them $(p=0.082)$. Similarly, there was no significant difference comparing the number of fibers

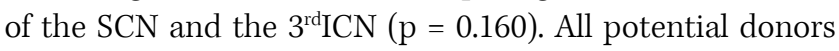

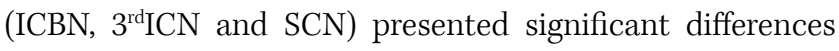
when compared with the LCMN $(\mathrm{p}<0.001)$. Detailed data on the statistical analysis are shown in Table 3. An example of fiber counting is shown in Figure 5.

\section{DISCUSSION}

Patients with a complete brachial plexus injury have anesthetic hands, exposing them to frequent secondary injuries such as burns and cuts. Even minor repetitive traumas

Table 1. Anatomical study data.

\begin{tabular}{lcccccccccc}
\hline Case & $\begin{array}{c}\text { Age } \\
\text { (years) }\end{array}$ & $\begin{array}{c}\text { Height } \\
(\mathrm{cm})\end{array}$ & $\begin{array}{c}\text { Weight } \\
(\mathrm{Kg})\end{array}$ & $\begin{array}{c}\text { Diameter } \\
\text { ICBN origin } \\
(\mathrm{mm})\end{array}$ & $\begin{array}{c}\text { Diameter } \\
\text { ICBN } \\
\text { coaptation } \\
(\mathrm{mm})\end{array}$ & $\begin{array}{c}\text { Number of } \\
\text { rami in origin }\end{array}$ & $\begin{array}{c}\text { Number of } \\
\text { branches }\end{array}$ & $\begin{array}{c}\text { Distance } \\
\text { origin - } \\
\text { branching } \\
(\mathrm{mm})\end{array}$ & $\begin{array}{c}\text { Distance } \\
\text { origin - } \\
\text { coaptation } \\
(\mathrm{mm})\end{array}$ & $\begin{array}{c}\text { Diameter } \\
\text { LCMN } \\
(\mathrm{mm})\end{array}$ \\
\hline Minimum & 33 & 147 & 36.4 & 0.5 & 1 & 1 & 1 & 0 & 36 \\
Maximum & 83 & 186 & 86 & 4 & 4 & 3 & 3 & 73 & 81 & 1.5 \\
Average & 62 & 166 & 59.5 & 2.1 & 2.7 & 1.1 & 2.2 & 23.8 & 54 \\
Median & 62 & 166 & 59.2 & 2 & 2.7 & 1 & 2 & 22.5 & 54 & 3.7 \\
SD & 14.3 & 10 & 12 & 0.7 & 0.8 & 0.4 & 0.5 & 17.9 & 10 & 1.1 \\
\hline
\end{tabular}

ICBN: intercostobrachial nerve; LCMN: lateral cord contribution to the median nerve. 


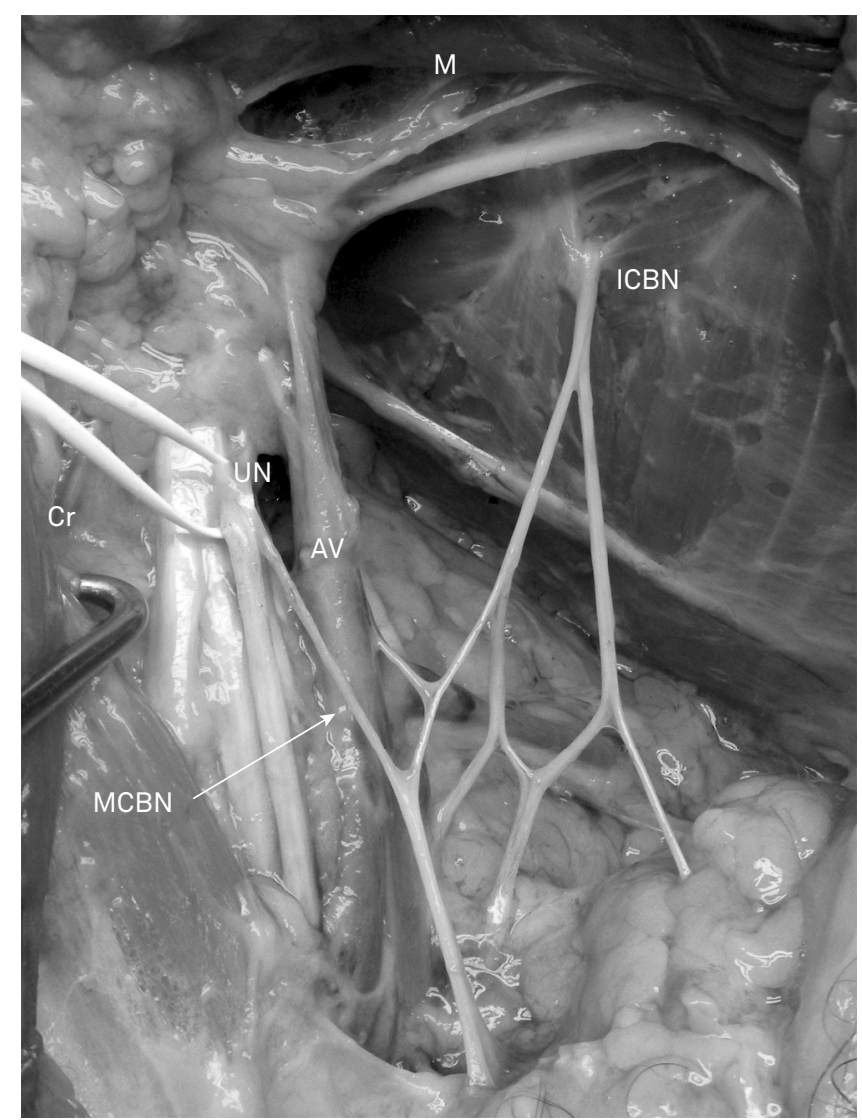

AV: axillary vein; Cr: cranial; ICBN: intercostobrachial nerve; M: medial; MBCN: medial brachial cutaneous nerve; UN: ulnar nerve

Figure 4. Photo of anatomical dissection: anterior view of the axilla after section and medial retraction of the pectoralis major muscle showing a communication/contribution of the intercostobrachial nerve contribution to the medial brachial cutaneous nerve, and the ulnar nerve repaired by a white silicone loop (From the authors archive).

Table 2. Fiber counting

\begin{tabular}{lcccc}
\hline Values & ICBN & $3^{\text {rd ICN }}$ & SCN & LCMN \\
\hline Minimum & 341 & 118 & 213 & 3622 \\
Maximum & 2035 & 1054 & 1727 & 7201 \\
Median & 910 & 456 & 525 & 5096 \\
Average & 984 & 470 & 693 & 5273 \\
SD & 517 & 266 & 511 & 1134
\end{tabular}

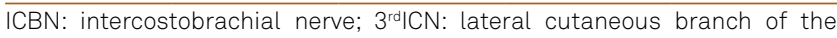
third intercostal nerve; SCN: supraclavicular nerve; LCMN: lateral cord contribution to the median nerve; SD: standard deviation.

Table 3. Comparative analysis* of number of fibers of the nerves.

\begin{tabular}{|c|c|c|c|}
\hline \multirow{2}{*}{ Variable } & \multicolumn{2}{|c|}{ Mean \pm SD } & \multirow{2}{*}{$p$} \\
\hline & $\mathrm{n} 1$ & n2 & \\
\hline$\left|C B N \times 3^{\text {rd }}\right| C N$ & $984 \pm 517$ & $470 \pm 266$ & 0.012 \\
\hline ICBN x SCN & $984 \pm 517$ & $692 \pm 511$ & 0.082 \\
\hline $3^{\text {rd }} \mid \mathrm{CN} \times \mathrm{SCN}$ & $470 \pm 266$ & $692 \pm 511$ & 0.160 \\
\hline ICBN x LCMN & $984 \pm 517$ & $5272 \pm 1134$ & $<0.001$ \\
\hline $3^{\text {rd }}$ ICN $\times$ LCMN & $470 \pm 266$ & $5272 \pm 1134$ & $<0.001$ \\
\hline$S C N \times L C M N$ & $692 \pm 511$ & $5272 \pm 1134$ & $<0.001$ \\
\hline
\end{tabular}

ICBN: intercostobrachial nerve; $3^{\text {rd }} \mathrm{CN}$ : lateral cutaneous branch of the third intercostal nerve; SCN: supraclavicular nerve; LCMN: lateral cord contribution to the median nerve; SD: standard deviation. * paired t-Test can result in lesions, infections and, in extreme cases, loss of tissue of the hand/fingers ${ }^{17,18}$.

Sensory reconstruction with intercostal and supraclavicular nerves can provide only a limited recovery of sensibility in the hand $d^{3,415,19,20,21,22,23,24}$. The need for better results for sensory recovery in the hand following brachial plexus surgery led us to search for a new alternative to previouslydescribed techniques. For this purpose, we focused this anatomical study on the feasibility of using the intercostobrachial nerve as a donor nerve to the lateral cord contribution to the median nerve.

Loukas et al. ${ }^{11}$ described that the ICBN is anatomically constant, and Maycock et al. ${ }^{25}$ reinforced the idea that the ICBN is responsible for the cutaneous innervation of the axilla region and the medial and posterior aspects of the arm. Thus, this nerve has an area of cortical representation closer to the hand area than the SCN and the $\mathrm{ICNs}^{26}$. This theoretically makes its use more favorable than other nerves (SCN and ICNs) in the sensory reconstruction of the brachial plexus, making the achievement of a better recovery and perception of stimuli likely.

Some authors have reported the absence of ICBN in up to $6 \%$ of subjects ${ }^{10,14,27}$, but the present study confirmed the presence of ICBN in all of the dissections. The ICBN was identified as a single trunk at its origin in $93.3 \%$ of the cases dissected. The description of this pattern ranged from $74 \%$ to $81.3 \%$ in other studies ${ }^{8,10,14,28}$.

In this study, the average diameter of the ICBN at its origin in the second intercostal space was $2.1 \pm 0.7 \mathrm{~mm}$, similar to the result of $1.89 \pm 0.44 \mathrm{~mm}$ described by Zhu et al. ${ }^{14}$. Furthermore, the distance between the origin and its apparent branching point was $23.8 \pm 17.9 \mathrm{~mm}$, values also similar to those obtained by other authors ${ }^{14,29}$.

As the cortical topography of the ICBN cutaneous territory is closer to the hand area than that of the other potential donors, we believe that the brain plasticity phenomenon is facilitated and, therefore, the results of hand sensory recovery should be better, both in terms of intensity and of localization of the stimulus perception.

Considering the number of fibers, the ICBN has a mean value greater than the other potential donors of the sensory axons. This could appear to be an advantage, but we have to remember that usually at least two ICNs are used when this is the chosen nerve transfer. When compared to the SCN, there was no significant difference between them. However, Ihara et al. ${ }^{19}$ reported better results in sensory restoration with the use of intercostal nerves than with the supraclavicular nerve. In conclusion, the advantages of using the ICBN are the proximity to the target, the better functional cortical topography and the representative number of fibers.

This study has some limitations. As our dissection of the ICBN aimed to reproduce the surgical conditions of a transfer to the LCMN, the dissection was not prolonged distally toward the arm and was interrupted when a sufficient length 

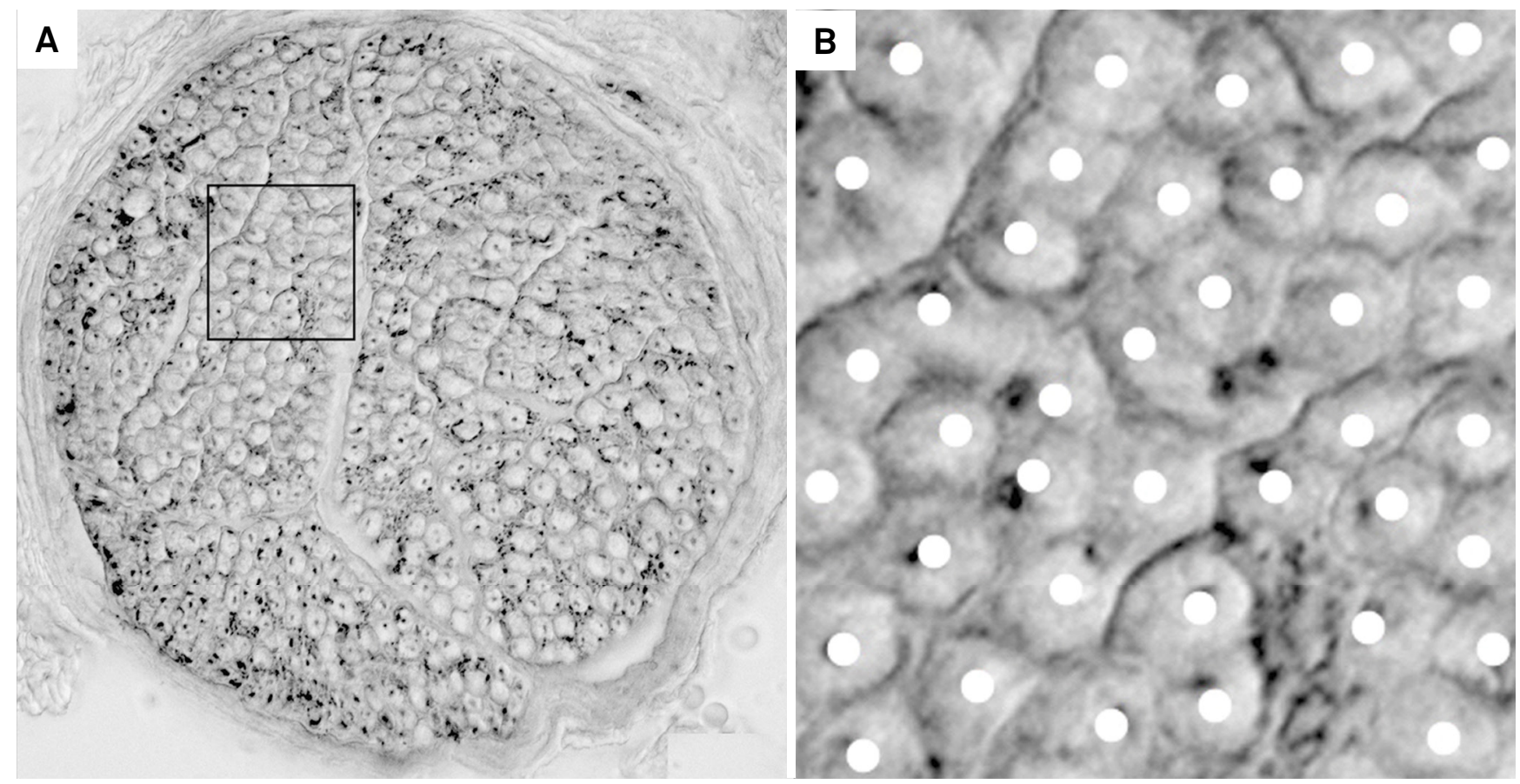

Figure 5. Microphotography of an intercostobrachial nerve section (a), showing the fibers and a selection area (b) to exemplify the fiber counting for the histomorphometric analysis (From the authors archive).

of the ICBN was achieved to reach the LCMN and the proposed technique could be applied. Thus, some of the communication of the ICBN with other nerves of the upper limb were probably not visualized and described, as they were in other studies ${ }^{11,12,14,30}$.

Despite the limitations, our study confirmed the anatomical feasibility of a direct coaptation, without interposition grafts and without tension, between the ICBN and the LCMN through dissection of an average extension of $54 \pm 10 \mathrm{~mm}$ from the origin of donor nerve to the coaptation point to the recipient nerve. The anatomical variations did not seem to be an obstacle to the use of this technique, which may be useful to restore protective sensation in the hands of patients with complete brachial plexus injury and may become an important contribution to the armament of nerve surgeons.

After completion of this anatomical study, a clinical study was started to evaluate the clinical applicability of the method.

\section{ACKNOWLEDGMENTS}

The authors gratefully acknowledge the great contribution of those who gave us permission to dissect their bodies and/or their families.

\section{References}

1. Brunelli G, Monini L. Neurotization of avulsed roots of brachial plexus by means of anterior nerves of cervical plexus. Clin Plast Surg. 1984;11(1):149-52.

2. Ihara K, Doi K, Sakai K, Kawai S, Kuwata N. Sensory reconstruction for total brachial plexus palsy of root-avulsed type. J Jpn Soc Surg Hand. 1992;9:472-5.

3. Kotani T, Toyoshima Y, Matsuda H Suzuki T, Ishizaki Y. The postoperative results of nerve transfer for the brachial plexus injuries with root avulsion. Seikeigeka. 1971;22:963-66.

4. Nagano A, Tsuyama N, Ochiai N, Hara T, Takahashi M. Direct nerve crossing with the intercostal nerve to treat avulsion injuries of the brachial plexus. J Hand Surg Am. 1989;14(6):980-5. https://doi.org/10.1016/S0363-5023(89)80047-4

5. Nakatuchi Y, Saitou S, Hosaka M, Tada H, Kamidaira M. Reconstruction of sensory function for brachial palsy. J Jpn Soc Surg Hand. 1988;5:156-60.

6. Williams PL, Bannister LH, Berry MM. Thoracic ventral rami. In: Williams PL, Bannister LH, Berry MM, editors. Gray's anatomy. 38th ed. London: Churchill Livingstone; 1999. p. 1275-76.
7. Morrow M. Segmental mastectomy and axillary dissection. In: Baker RJ, Fischer JE, editors. Mastery of surgery. 4th ed. Philadelphia: Lippincott Williams and Wilkins; 2001. p. 588-96.

8. Cunnick GH, Upponi S, Wishart GC. Anatomical variants of the intercostobrachial nerve encountered during axillary dissection. Breast. 2001;10(2):160-2. https://doi.org/10.1054/brst.2000.0226

9. Ghaderi B, Hoenig JM, Dado D, Angelats J, Vandevender D. Incidence of intercostobrachial nerve injury after transaxillary breast augmentation. Aesthet Surg J. 2002;22(1):26-32. https://doi.org/10.1067/maj.2002.121957

10. Kubala O, Prokop J, Jelínek P, Ostruszka P, Tošenovský J, Ihnát P et al. [Anatomic-surgical study of intercostobrachial nerve (ICBN) course in axilla during I and II level of axilla clearance in breast cancer and malignant melanoma]. Rozhl Chir. 2013;92(6):320-9. Czech.

11. Loukas M, Hullett J, Louis RG Jr, Holdman S, Holdman D. The gross anatomy of the extrathoracic course of the intercostobrachial nerve. Clin Anat. 2006;19(2):106-11. https://doi.org/10.1002/ca.20226 
12. O'Rourke MGE, Tang TS, Allison SI, Wood W. The anatomy of the extrathoracic intercostobrachial nerve. Aust N Z J Surg. 1999;69(12):860-4. https://doi.org/10.1046/j.1440-1622.1999.01718.x

13. Taira N, Shimozuma K, Ohsumi S, Kuroi K, Shiroiwa T, Watanabe T et al. Impact of preservation of the intercostobrachial nerve during axillary dissection on sensory change and health-related quality of life 2 years after breast cancer surgery. Breast Cancer. 2014;21(2):183-90. https://doi.org/10.1007/s12282-012-0374-x

14. Zhu JJ, Liu KF, Zhang PL, Yang JZ, Wang J, Qin Y et al. Anatomical information for intercostobrachial nerve preservation in axillary lymph node dissection for breast cancer. Genet Mol Res. 2014;13(4):9315-23. https://doi.org/10.4238/2014.January.24.13

15. Hattori Y, Doi K, Sakamoto S, Yukata K. Sensory recovery of the hand with intercostal nerve transfer following complete avulsion of the brachial plexus. Plast Reconstr Surg 2009;123(1):276-83. https://doi.org/10.1097/PRS.0b013e31819348a7

16. Levy BF, Cunha JC, Chadi G. Cellular analysis of S100Beta and fibroblast growth factor-2 in the dorsal root ganglia and sciatic nerve of rodents: focus on paracrine actions of activated satellite cells after axotomy. Int J Neurosci. 2007;117(10):1481-503. https://doi.org/10.1080/15569520701502716

17. Bertelli JA. Distal sensory nerve transfers in lower-type injuries of the brachial plexus. J Hand Surg Am. 2012;37(6):1194-9. https://doi.org/10.1016/j.jhsa.2012.02.047

18. Ruchelsman DE, Price AE, Valencia H, Ramos LE, Grossman JA. Sensory restoration by lateral antebrachial cutaneous to ulnar nerve transfer in children with global brachial plexus injuries. Hand (NY). 2010;5(4):370-3. https://doi.org/10.1007/s11552-010-9284-6

19. Ihara K, Doi K, Sakai K, Kuwata N, Kawai S. Restoration of sensibility in the hand after complete brachial plexus injury. J Hand Surg. 1996;21(3):381-6. https://doi.org/10.1016/S0363-5023(96)80348-0
20. Kawai H, Kawabata H, Masada K, Ono K, Yamamoto K, Tsuyuguchi Y et al. Nerve repairs for traumatic brachial plexus palsy with root avulsion. Clin Orthop Relat Res. 1988;(237):75-86.

21. Millesi H. Surgical management of brachial plexus injuries. J Hand Surg. 1977;2(5):367-78. https://doi.org/10.1016/S0363-5023(77)80046-4

22. Narakas AO, Hentz VR. Neurotization in brachial plexus injuries: indication and results. Clin Orthop Relat REs. 1988;(237):43-56.

23. Ogino T, Naito T. Intercostal nerve crossing to restore elbow flexion and sensibility of the hand for a root avulsion type of brachial plexus injury. Microsurgery. 1995;16(8):571-7. https://doi.org/10.1002/micr.1920160812

24. Sedel $L$. The results of surgical repair of brachial plexus injuries. J Bone Joint Surg. 1982;64(1):54-66.

25. Maycock LA, Dillon P, Dixon JM. Morbidity related to intercostobrachial nerve damage following axillary surgery for breast cancer. Breast. 1998;7(4):209-12. https://doi.org/10.1016/S0960-9776(98)90110-2

26. Penfield W, Boldrey E. Somatic motor and sensory representation in the cerebral cortex of man as studied by electrical stimulation. Brain. 1937;60(4):389-443. https://doi.org/10.1093/brain/60.4.389

27. Andersen KG, Aasvang EK, Kroman N, Kehlet H. Intercostobrachial nerve handling and pain after axillary lymph node dissection for breast cancer. Acta Anaesthesiol Scand. 2014;58(10):1240-8. https://doi.org/10.1111/aas.12393

28. Khan A, Chakravorty A, Gui GP. In vivo study of the surgical anatomy of the axilla. Br J Surg. 2012;99(6):871-7. https://doi.org/10.1002/bjs.8737

29. Hwang K, Huan F, Hwang SW, Kim SH, Han SH. The course of the intercostobrachial nerve in the axillary region and as it is related to transaxillary breast augmentation. Ann Plast Surg. 2014;72(3):337-9. https://doi.org/10.1097/SAP.0b013e31825c07ba

30. Clemente CD. Ventral primary divisions of the spinal nerves. In: Clemente CD, editor. Gray's anatomy. 30th edn. Baltimore: Williams and Wilkins; 1995. p. 1223-5. 